\title{
Impossible but true: complete transection of common bile duct treated with ERCP| percutaneous biliodigestive rendezvous
}

Bile duct injuries after laparoscopic cholecystectomy have been reported even after surgical procedures performed by expert surgeons. Mean rates have plateaued in the past 10 years $(0.30 \%-$ $0.60 \%)$. The Hannover classification (2015) is a modification of the Strasberg-Bismuth classification and allows a distinction between small injuries (bile leakage from the cystic duct or aberrant right sectoral branch) and serious injuries inflicted during laparoscopic cholecystectomy [1,2]. The Hannover classification also provides discriminators for the localization of tangentially or completely transected bile ducts above or below the bifurcation of the hepatic duct, which is a major drawback of other classification systems.

Small injuries are usually treated with endoscopic retrograde cholangiopancreatography (ERCP) in which plastic stents are placed in the affected branch for a mean of 3-6 months and then extracted. Severe injuries, on the other hand, are always treated with surgery (Roux-en-Y choledocho-/hepaticojejunostomy or end-to-end laparoscopic reconstruction) [3-5]. So far, no nonsurgical approaches have been reported, except for one short report on leakage after hepatobiliary and pancreatic surgery (totally radiological percutaneous rendezvous).

A 60-year-old man who had undergone open cholecystectomy in another hospital and been discharged 2 days earlier was admitted to the emergency room of our hospital for acute abdomen, cholangitis, and a collection of bilious-looking fluid in the surgical drainage $(>700 \mathrm{~mL}$ ) day). Abdominal computed tomography revealed a large perihepatic fluid collection and magnetic resonance imaging showed complete, severe leakage from the common bile duct, type D2 (Hannover classification) ( $\triangleright$ Video 1$)$. Laboratory investigation revealed high levels of bilirubin (total $12.00 \mathrm{mg} / \mathrm{dL}$, direct

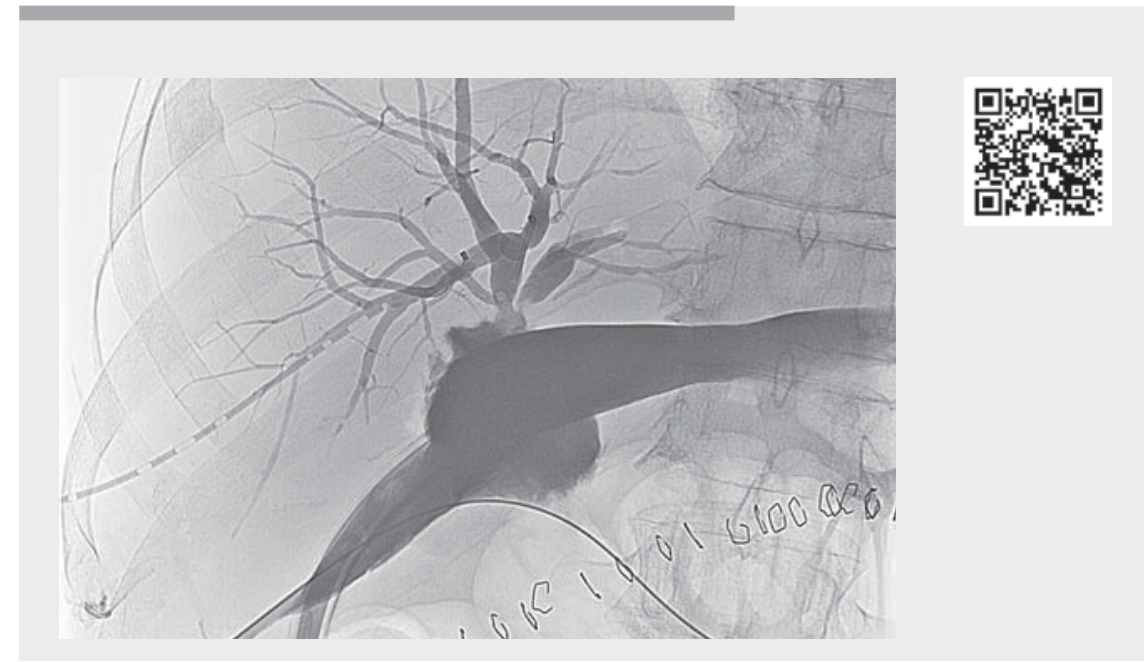

Video 1 Complete transection of the common bile duct. Two plastic pig-tailed stents were inserted in the right and left main hepatic duct, and were later replaced with self-expandable metallic ones.

$10.00 \mathrm{mg} / \mathrm{dL})$, leukocytosis $(22,000 \times$ $\left.10^{3} / \mu \mathrm{L}\right)$, and high levels of inflammatory markers.

The patient was in a severely compromised clinical condition. The leakage was due to complex iatrogenic duct transection with excluded liver segments. Given this critical scenario, emergency ERCP/ percutaneous biliodigestive rendezvous was attempted (\Video 1 ). An alternative surgical approach was ready to be employed if the first approach failed.

By means of a gooseneck snare (Medtronic), we managed to achieve our aim. Two plastic pig-tailed stents (8.5 Fr, $12 \mathrm{~cm}$ ) were successfully inserted in the right and left main hepatic duct and a bile bag draining from the subhepatic space was left ( Video 1 ). In the following days cholangiography showed an improvement in the biliary leakage and a progressive reduction in the output of the bile bag. The second step was replacement of the plastic stents with self-expandable metallic ones $(10 \mathrm{Fr}, 12 \mathrm{~cm})$ ( $\vee$ Video 1).

The patient was discharged uneventfully 1 month later, and at 2-month follow-up cholangiography showed complete reconstruction of the biliary tree without any evidence of leakage ( $\triangleright$ Video 1 ).

Endoscopy_UCTN_Code_TTT_1AR_2AG

\section{Competing interests}

The authors declare that they have no conflict of interest.

The authors

Valeria D’Ovidio' ${ }^{1}$, Valentina Pompa², Nicola Maltzeff'2, Giulio Sodani², Roberto

Cancellieri $^{2}$, Marco Emilio Bazuro ${ }^{1}$

1 Gastrointestinal Endoscopy Unit, S. Eugenio Hospital, Rome, Italy

2 Interventional Radiology Unit, S. Eugenio Hospital, Rome, Italy

\section{Corresponding author}

Valeria D'Ovidio, MD

Gastrointestinal Endoscopy Unit, Ospedale

Sant'Eugenio, Rome, Italy

valeria.dovidio@aslroma2.it 


\section{References}

[1] Strasberg SM, Hertl M, Soper NJ. An analysis of the problem of biliary injury during laparoscopic cholecystectomy. J Am Coll Surg 1995; 180: 101-125

[2] Chun K. Recent classifications of the common bile duct injury. Korean J Hepatobiliary Pancreat Surg 2014; 18: 69-72

[3] de Reuver PR, Busch OR, Rauws EA et al. Long-term results of a primary end-to-end anastomosis in peroperative detected bile duct injury. J Gastrointest Surg 2007; 11: 296-302

[4] Kwak BK, Choi H], You YK et al. Laparoscopic end-to-end biliary reconstruction with Ttube for transected bile duct injury during laparoscopic cholecystectomy. Ann Surg Treat Res 2019; 96: 319-325
[5] Mansueto G, Gatti FL, Boninsegna E et al. Biliary leakage after hepatobiliary and pancreatic surgery: a classification system to guide the proper percutaneous treatment. Cardiovasc Intervent Radiol 2020; 43: $302-$ 310

\section{Bibliography}

Endoscopy 2022; 54: E427-E428

DOI 10.1055/a-1559-1397

ISSN 0013-726X

published online 8.9.2021

(c) 2021. Thieme. All rights reserved.

Georg Thieme Verlag KG, Rüdigerstraße 14

70469 Stuttgart, Germany

\section{ENDOSCOPY E-VIDEOS}

https://eref.thieme.de/e-videos

口回 Endoscopy E-Videos is an open access online section, 回艘: reporting on interesting cases and new techniques in gastroenterological endoscopy. All papers include a high quality video and all contributions are freely accessible online. Processing charges apply (currently EUR 375), discounts and wavers acc. to HINARI are available.

This section has its own submission website at

https://mc.manuscriptcentral.com/e-videos 